\title{
Variability and genetic differentiation among Anopheles (Ano.) intermedius Chagas, 1908 and Anopheles (Ano.) mattogrossensis Lutz \& Neiva, 1911 (Diptera: Culicidae) from the Brazilian Amazon
}

\author{
Joselita Maria Mendes dos Santos/ ${ }^{+}$, Gloria Alicia Diaz Rodriguez*, \\ Juracy de Freitas Maia, Wanderli Pedro Tadei
}

Instituto Nacional de Pesquisas da Amazônia, Coordenação de Pesquisas em Ciências da Saúde, Av. André Araújo 2936, 69011970 Manaus, AM, Brasil *Dirección Regional de Salud de Loreto, Dirección Ejecutiva de Salud Ambiental, Iquitos, Peru

Anopheles (Anopheles) intermedius and Anopheles (Ano.) mattogrossensis are Brazilian anopheline species belonging to the scarcely studied Anopheles subgenus. Few studies have been done on the genetic differentiation of these species. Both species have been found infected by Plasmodium and are sympatric with other anopheline species from the Nyssorhynchus subgenus. Eighteen enzymatic loci were analyzed in larval specimens of An. intermedius and An. mattogrossensis aiming to estimate the variability and genetic differentiation between these species. An. mattogrossensis population showed higher genetic variability $(P=44.4$ and $H o=0.081 \pm 0.031)$ than that of An. intermedius $(P=33.3$ and $H o=0.048 \pm 0.021)$. Most analyzed loci showed genotypic frequencies according to Hardy-Weinberg equilibrium, except for LAP1 and LAP2 in An. intermedius, and EST1 and PGM loci in An. mattogrossensis. The genetic distance between these species $(D=0.683)$ was consistent with the inter-specific values reported for Anopheles subgenus. We verified that the polymorphism and heterozygosity percentile values found in both species and compared to those in the literature, showed no relation between the level of isozyme variability and geographical distribution. The low variability found in these two species is probably more related to the niche they occupy than to their geographic distribution.

Key words: Anopheles intermedius - Anopheles mattogrossensis - isozymes - malaria - Amazon

Information concerning variability and genetic differentiation in species of the subgenus Anopheles is very scanty in Brazil, even thought they include malaria vector species in other American neighboring countries (Rodriguez et al. 2000, Santos et al. 2003). An. intermedius and An. mattogrossensis show a wide geographical distribution in South America (Bolivia, Brazil, Peru, Colombia, Venezuela, Trinidad, and Guiana), being most abundant in forested areas like the Brazilian Amazon Region (Forattini 1962). Larvae are mostly found in shaded lagoons, marshes, floodplains, residual puddles in the forest, and river stretches in the middle of the bushes. Females are exophilic and zoophilic, and there have been no evidence of being able to transmit malaria (Forattini 1962, Belkin et al. 1971). However, dissection and ELISA analyses revealed that these species were infected by Plasmodium (Arruda et al. 1986, Tadei \& Dutary-Thatcher 2000). In an area where anthropic modified environments are rapidly spreading like the Brazilian Amazon, this species maybe under vigilance as able to transmit malaria.

This work aims to analyze the isoenzimatic genetic variability of An. (Ano.) intermedius and An. (Ano.) mattogrossensis and to compare to results found for species of the subgenus Nyssorhynchus.

Financial support: Program for the Protection of Brazilian Rainforest/MCT, Subprogram C\&T/PPD G-7, Fapeam, CTPETRO ${ }^{+}$Corresponding author. E-mail: jsantos@inpa.gov.br Received 3 January 2005

Accepted 14 September 2005

\section{MATERIALS AND METHODS}

Specimens and collection sites - Wild-caught An. mattogrossensis adult females were collected on cattlebait in Lake Janauari (right margin of the Negro River, near Manaus), Amazonas (0308'00.5'S, 6000'34.7'W). An. intermedius adult females were captured on humanbait in forest border areas close to domiciles (30 m approximately) of Highway Pacoval, km 4, Macapá, Amapá $\left(00^{\circ} 02^{\prime} 19.8^{\prime} \mathrm{N}, 5^{\circ} 03^{\prime} 40.7^{\prime \prime} \mathrm{W}\right)$, between 18:00 and 22:00 h. Females mosquitoes were isolated for individual oviposition. After hatching, larvae from individual progenies were maintained at $26^{\circ} \pm 1^{\circ} \mathrm{C}$ until 4th instar when they were frozen at $-70^{\circ} \mathrm{C}$ and underwent isoenzymatic analyses, according to Santos et al. (1981). Fourth instar larvae were employed in all the systems, except for $\alpha-G P D H$, in which adults were used. Morphologic identifications were done on egg and adults based on Cova-Garcia and Sutil (1977) and Consoli and Lourenço-de-Oliveira (1994).

Isoenzymatic analyses - Eighteen loci were analyzed: esterase (EST1, EST3 - E.C.3.1.1.1), leucine aminopeptidase (LAP1, LAP2, LAP3 - E.C.3.4.11.1), $\alpha$-glycerophosphate dehydrogenase ( $\alpha$-GPD - E.C.1.1.1.8), phosphoglucose isomerase (PGI - E.C.5.3.1.9), alcohol dehydrogenase (ADH - E.C.1.1.1.1), aldehyde oxidase (AO E.C.1.2.3.1), isocitrate dehydrogenase (IDH - E.C.1.1.1.42), 6-phosphogluconate dehydrogenase (6-PGD-E.C.1.1.1.44), malate dehydrogenase (MDH - E.C.1.1.1.37), malic enzyme (ME - E.C.1.1.1.40), hexokinase (HK1, HK2, HK3, HK4 - E.C.2.7.1.1) and phosphoglucomutase (PGM - E.C.5.4.2.2). Electrophoresis was performed in starch gel $(12.5 \%)$ and starch-agarose (2 and 1\%, respectively) 
following Steiner and Joslyn (1979), Lima and Contel (1990) and Santos et al. (1996). For each locus, the most frequent electromorph was designated the 100 allele and all other alleles were measured relative to it.

Statistic analyses - Approximately three individuals from each of 30 progenies were used for each enzymatic system, in a total of 100 individuals. Genetic variability for each species was estimated using the mean number of alleles per locus, proportion of polymorphic loci (P), mean observed heterozygosity (Ho), and expected heterozygosity (He) using the Biosys-1 program (Swofford \& Selander 1981). Conformance tests for Hardy-Weinberg equilibrium was done by Chi-square test using the Biosys-1 program and by G-square test (Monjeló 2005). The no-criteria option from the Biosys-1 program was used to estimate the percentage of polymorphic loci. Thus, a locus was considered polymorphic if any variation was observed, independent of the frequency of alleles detected. T-student test was used to assess the significance level of the mean observed and expected heterozygosities between An. intermedius and An. mattogrossensis. Genetic distance was calculated according to Nei (1978).

\section{RESULTS}

Five out of the 18 loci analyzed presented polymorphism for both species: EST1, LAP1, LAP2, LAP3, and PGM. PGM locus was the one presenting the largest number of alleles when considering both species (Table I). EST3, 6PGD, and MDH loci were polymorphic only for An. mattogrossensis, whereas IDH locus was polymorphic only for An. intermedius. IDH presented three alleles $\mathrm{IDH}_{106}, \mathrm{IDH}_{100}$ and $\mathrm{IDH}_{92}$. In An. mattogrossensis only $\mathrm{IDH}_{92}$ was detected (Fig. 1). $\mathrm{IDH}_{92}$ was considered a diagnostic locus, as well as HK1, HK2, HK3, and HK4 loci, which were monomorphic for the HK $1_{100}, \mathrm{HK} 2_{100}$, HK $3_{100}$ and HK $4_{100}$ alleles in An. intermedius and for the $\mathrm{HK} 1_{94}, \mathrm{HK}_{2}, \mathrm{HK}_{94}$ and $\mathrm{HK} 4_{98}$ alleles in An. mattogrossensis (Fig. 2). For the PGM locus, the $\mathrm{PGM}_{100}$ allele was common in the two species (0.929 for An. intermedius). The $\mathrm{PGM}_{105}$ allele was only detected in An. intermedius while PGM $_{97}$ was detected only in An. mattogrossensis (Table I).
Both species showed most loci in Hardy-Weinberg equilibrium as demonstrated by Chi-square and G-square results (Table I). For most loci $\chi^{2}$ and $\mathrm{G}^{2}$ were not significant except for loci LAP1 $\left(\chi^{2}=56.998, \mathrm{G}^{2}=7.953\right.$, D.F. $=1, \mathrm{P}<0.01)$ and LAP2 $\left(\chi^{2}=11.692, \mathrm{G}^{2}=6.961\right.$, D.F. $=1, \mathrm{P}<0.01)$ for An. intermedius population, and EST1 $\left(\chi^{2}=10.120, \mathrm{G}^{2}=7.732\right.$, D.F. $\left.=1, \mathrm{P}<0.01\right)$ and PGM $\left(\chi^{2}=5.071, \mathrm{G}^{2}=5.756\right.$, D.F. $\left.=1, \mathrm{P}<0.05\right)$ loci for $\mathrm{An}$. mattogrossensis (Table I). Most of the Hardy-Weinberg equilibrium deviations were probably due to excess of observed homozygous individuals, in comparison with the expected numbers.

TABLE I

Isoenzymatic allelic frequency for 18 loci for Anopheles intermedius and An. mattogrossensis

\begin{tabular}{lccc}
\hline & & \multicolumn{2}{c}{ Species } \\
\cline { 3 - 4 } Locus & Allele & An. intermedius & An. mattogrossensis \\
\hline EST1 & $\mathrm{n}$ & 101 & 106 \\
& 100 & 0.856 & 0.858 \\
& 98 & 0.144 & 0.142 \\
$\mathrm{G}^{2}$ & & $1.461^{n s}$ & $7.732^{a}$ \\
$\chi^{2} \mathrm{H}-\mathrm{H}-\mathrm{W}$ & & $2.729^{n s}$ & $10.120^{a}$ \\
EST3 & $\mathrm{n}$ & 101 & 93 \\
& 100 & 1.000 & 0.871 \\
& 98 & 0.000 & 0.129 \\
$\mathrm{G}^{2}$ & & - & $0.210^{n s}$ \\
$\chi^{2} \mathrm{H}-\mathrm{W}-\mathrm{W}$ & & - & $0.226^{n s}$ \\
LAP1 & $\mathrm{n}$ & 87 & 133 \\
& 100 & 0.983 & 0.970 \\
& 97 & $0.017^{n}$ & 0.030 \\
$\mathrm{G}^{2} \mathrm{H}-\mathrm{W}$ & & $7.953^{a}$ & $1.658^{n s}$ \\
$\chi^{2} \mathrm{H}-\mathrm{W}$ & & $56.998^{a}$ & $0.111^{n s}$ \\
$L A P 2$ & $\mathrm{n}$ & 90 & 131 \\
& 100 & $0.917^{a}$ & 0.870 \\
& 97 & $0.083^{a}$ & 0.130 \\
$\mathrm{G}^{2} \mathrm{H}-\mathrm{W}$ & & $6.961^{a}$ & $1.786^{n s}$ \\
$\chi^{2} \mathrm{H}-\mathrm{W}$ & & $11.692^{a}$ & $2.089^{n s}$ \\
& & &
\end{tabular}

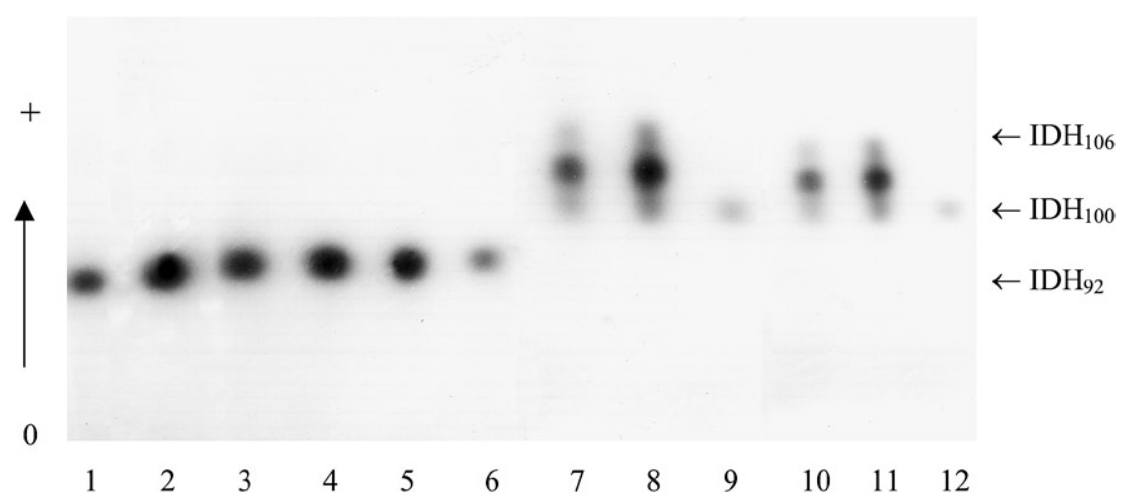

Fig. 1: starch gel electrophoresis isocitrate dehydrogenase isoenzymatic profiles for 4th-instar larvae of Anopheles mattogrossensis (samples 1 to 6 ) and An. intermedius (samples 7 to 12). Tris-citrate buffer system, pH 7.1. 


\begin{tabular}{|c|c|c|c|}
\hline \multirow[b]{2}{*}{ Locus } & \multirow[b]{2}{*}{ Allele } & \multicolumn{2}{|c|}{ Species } \\
\hline & & An. intermedius & An. mattogrossensis \\
\hline \multirow[t]{3}{*}{$L A P 3$} & $\mathrm{n}$ & 77 & 114 \\
\hline & 100 & 0.870 & 0.952 \\
\hline & 96 & 0.130 & 0.048 \\
\hline \multirow{6}{*}{$\begin{array}{l}\mathrm{G}^{2} \mathrm{H}-\mathrm{W} \\
\chi^{2} \mathrm{H}-\mathrm{W} \\
I D H\end{array}$} & & $0.065^{n s}$ & $0.688^{n s}$ \\
\hline & & $0.061^{n s}$ & $0.265^{n s}$ \\
\hline & $\mathrm{n}$ & 123 & 100 \\
\hline & 106 & 0.016 & 0.000 \\
\hline & 100 & 0.956 & 0.000 \\
\hline & 92 & 0.028 & 1.000 \\
\hline \multirow{5}{*}{$\begin{array}{l}\mathrm{G}^{2} \mathrm{H}-\mathrm{W} \\
\chi^{2} \mathrm{H}-\mathrm{W} \\
6 P G D\end{array}$} & & $1.012^{n s}$ & - \\
\hline & & $0.244^{n s}$ & - \\
\hline & $\mathrm{n}$ & 117 & 101 \\
\hline & 106 & 0.000 & 0.119 \\
\hline & 100 & 1.000 & 0.881 \\
\hline \multirow{5}{*}{$\begin{array}{l}\mathrm{G}^{2} \mathrm{H}-\mathrm{W} \\
\chi^{2}{ }_{\mathrm{H}-\mathrm{W}} \\
M D H\end{array}$} & & - & $0.331^{n s}$ \\
\hline & & - & $0.365^{n s}$ \\
\hline & $\mathrm{n}$ & 104 & 113 \\
\hline & 100 & 1.000 & 0.987 \\
\hline & 94 & 0.000 & 0.013 \\
\hline \multirow{6}{*}{$\begin{array}{l}\mathrm{G}^{2} \mathrm{H}-\mathrm{W} \\
\chi^{2} \mathrm{H}-\mathrm{W} \\
\mathrm{PGM}\end{array}$} & & - & $0.028^{n s}$ \\
\hline & & - & $0.014^{n s}$ \\
\hline & $\mathrm{n}$ & 106 & 103 \\
\hline & 105 & 0.071 & 0.000 \\
\hline & 100 & 0.929 & 0.728 \\
\hline & 97 & 0.000 & 0.272 \\
\hline \multirow{5}{*}{$\begin{array}{l}\mathrm{G}^{2} \mathrm{H}-\mathrm{W} \\
\chi^{2} \mathrm{H}-\mathrm{W} \\
H K 1\end{array}$} & & $1.066^{n s}$ & $5.756^{b}$ \\
\hline & & $0.571^{n s}$ & $5.071^{b}$ \\
\hline & $\mathrm{n}$ & 104 & 101 \\
\hline & 100 & 1.000 & 0.000 \\
\hline & 94 & 0.000 & 1.000 \\
\hline \multirow[t]{3}{*}{$H K 2$} & $\mathrm{n}$ & 104 & 101 \\
\hline & 100 & 1.000 & 0.000 \\
\hline & 95 & 0.000 & 1.000 \\
\hline \multirow[t]{3}{*}{$H K 3$} & $\mathrm{n}$ & 104 & 101 \\
\hline & 100 & 1.000 & 0.000 \\
\hline & 94 & 0.000 & 1.000 \\
\hline \multirow[t]{3}{*}{$H K 4$} & $\mathrm{n}$ & 104 & 101 \\
\hline & 100 & 1.000 & 0.000 \\
\hline & 98 & 0.000 & 1.000 \\
\hline
\end{tabular}

ME, PGI, ADH, AO, and $\alpha$-GPD were monomorphic for the two species. Degrees of freedom is equal to one for all loci except IDH locus $(\mathrm{DF}=3)$. n: sample size; $n s$ : not significant; $a$ : $\mathrm{P}<$ $0.01 ; b: \mathrm{P}<0.05 ;-:$ not calculated.
Two-banded heterozygotes were stained in EST, LAP, and PGM indicating a monomeric structure for these enzymes, and IDH, 6PGD, and MDH showed three bands in the heterozygotes, a pattern typical of dimeric enzymes. The enzymes ME, HK, PGI, ADH, AO, and $\alpha$-GPD were monomorphic for both species (i.e. no heterozygote individual was detected).

The results of the average number of samples and of alleles per locus were similar between An. intermedius and An. mattogrossensis species $(95.7 \pm 4.8$ and $98.4 \pm 5.5 ; 1.4$ \pm 0.1 and $1.4 \pm 0.1$, respectively). Higher polymorphism and heterozygosity were found in An. mattogrossensis ( $\mathrm{P}$ $=44.4 ; \mathrm{He}=0.081 \pm 0.031)$. An. intermedius presented lower polymorphism $(\mathrm{P}=33.3)$ and heterozygosity $(\mathrm{He}$ $=0.048 \pm 0.021$ ) values (Table II). However, there is not a statistically significant difference between the observed and expected mean heterozygosities of the two species (Student's $\mathrm{t}=-0.876,-0.956$, and $\mathrm{P}=0.389,0.348$, respectively).

A comparative analysis of genetic variability parameters between species of the subgenera Nyssorhynchus and Anopheles, based on the present work and published data, is shown in Table III. Genetic distance index between An. intermedius and An. mattogrossensis was 0.683, in conformity with previous values found for interspecific variation in the genus Anopheles.

\section{DISCUSSION}

An. intermedius and An. mattogrossensis are species belonging to the subgenus Anopheles. Because these species do not present epidemiological importance and are of restrict geographical distribution in Brazil, little is known about their population genetics. Isoenzymatic analyses found about $30 \%$ polymorphic loci for both species out of 18 loci. Five monomorphic loci were considered diagnostic, i.e. could separate An. intermedius from An. mattogrossensis. These were IDH1, HK1, HK2, HK3, and HK4. Fritz et al. (1995) identified three diagnostic loci for AO, IDH2, and ME, which separate An. nuneztovari, An. rangeli, and An. trinkae, species of the Nys-sorhynchus subgenus, with a closer phylogenetic relationship between the latter two. IDH1 and IDH2 also separated the A and B forms of An. quadrimaculatus complex (Lanzaro et al. 1990). According to these authors, the analyses of the genotypic frequencies in these two loci revealed a significant deficiency of heterozygotes, consistent with the Wahlund effect, observed when sympatric populations with limited

TABLE II

Genetic variability estimate at 18 loci of the Anopheles intermedius and An. mattogrossensis populations

\begin{tabular}{|c|c|c|c|c|c|}
\hline \multirow[b]{2}{*}{ Population } & \multirow{2}{*}{$\begin{array}{c}\text { Mean sample } \\
\text { size/locus }\end{array}$} & \multirow{2}{*}{$\begin{array}{l}\text { Mean no. of } \\
\text { alleles/locus }\end{array}$} & \multirow{2}{*}{$\begin{array}{c}\% \text { polymorphic } \\
\operatorname{loci}^{a}\end{array}$} & \multicolumn{2}{|c|}{ Mean heterozygosity } \\
\hline & & & & Observed & Expected $^{b}$ \\
\hline An. intermedius & $95.7 \pm 4.8$ & $1.4 \pm 0.1$ & 33.3 & $0.048 \pm 0.021$ & $0.049 \pm 0.020$ \\
\hline An. mattogrossensis & $98.4 \pm 5.5$ & $1.4 \pm 0.1$ & 44.4 & $0.081 \pm 0.031$ & $0.082 \pm 0.029$ \\
\hline Student's t & & & & $\begin{array}{l}-0.876(26) \\
\mathrm{P}=0.389^{n s}\end{array}$ & $\begin{array}{l}-0.956(26) \\
\mathrm{P}=0.348^{n s}\end{array}$ \\
\hline
\end{tabular}

$a$ : a locus was considered polymorphic if more than one allele was detected (Swofford \& Selander 1981); $b$ : expected heterozygosity of Hardy-Weinberg; Nei's unbiased estimate (Nei 1978); ns: not significant; degrees of freedom within parentheses. 


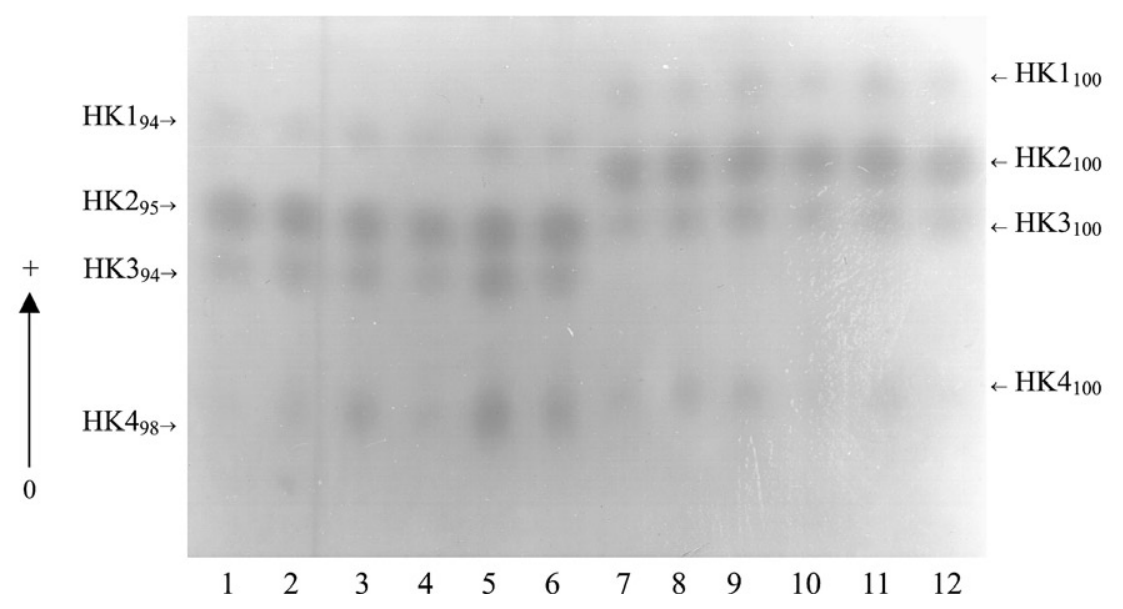

Fig. 2: starch gel electrophoresis of hexokinase isoenzymatic profiles for 4th-instar larvae of Anopheles mattogrossensis (samples 1 to 6) and Anopheles intermedius (samples 7 to 12). Tris-citrate buffer system, pH 7.1.

gene flow are considered as a unique population. However, the lack of heterozygotes found in three of the four loci for An. intermedius and An. mattogrossensis cannot be accounted for the Wahlund effect, since populations come from different sites apart $2000 \mathrm{~km}$ approximately.

Polymorphism values observed for An. intermedius ( $\mathrm{P}$ $=33.3)$ and An. mattogrossensis $(\mathrm{P}=44.4)$ are similar to those found for other species of the subgenus Anopheles, such as An. franciscanus $(\mathrm{P}=33.3)$ and An. crucians $(\mathrm{P}$ $=39.4$ ) (Manguin et al. 1995). However, in the subgenus Nyssorhynchus, high levels of polymorphism (P > 55.0) were reported for one Brazilian population of An. albitarsis (Narang 1980), three populations of An. albimanus from the Northern Colombia (Narang et al. 1991) and four populations of An. darlingi from the Brazilian Amazon (Santos et al. 1999). Carvalho-Pinto and Lourenço-deOliveira (2004) found higher polymorphism levels on $A n$. cruzii Brazilian populations of the subgenus Kerteszia $(\mathrm{P}=$ 72.7 - 81.8). Extensive genetic variability in mosquitoes is thought to have implications on malaria control programs, since it could represent plasticity to respond to selection pressure of insecticides (Tadei 1993). Small polymorphism values were registered for Southern Colombian populations of An. albimanus $(16 \leq \mathrm{P} \leq 40)$. An. albimanus low polymorphism values could be due to the relation between the habitat and the reduced population size in the estuaries, which can promote inbreeding, resulting in genetic drift or marginal effect and selection. Low polymorphism values were also detected in the An. triannulatus population from Lake Janauari $(25 \leq \mathrm{P} \leq 56.3$, Brazilian Amazon, Santos et al. 2004), in An. nuneztovari from Highway BR-174AM, km $204(\mathrm{P}=31.3$, Brazilian Amazon, Scarpassa et al. 1999), and An. aquasalis population from Rio de Janeiro ( $\mathrm{P}=34$, Narang 1980), of restricted distribution in brackish water on estuarine habitats. For the An. aquasalis population, polymorphism value was similar to that found for An. intermedius (Table III). The low polymorphism in An. triannulatus and An. nuneztovari populations (Scarpassa et al. 1999, Santos et al. 2004) could be related to the fact that collection was performed during dry season, when breeding sites are drastically reduced, leading to mosquitoes population density decrease and favoring inbreeding, that could result in genetic drift or marginal effect and, selection. Low genetic variation was also found in An. mattogrossensis based on mitochondrial DNAsequencing, when compared with six anopheline species of the subgenus Nyssorhynchus. The same study also showed lower adenine and thymine rates on An. mattogrossensis specimens than on those from subgenus Nyssorhynchus, possibly suggesting a lower mutation rate (Borges $\mathrm{R}$ and Santos JMM, unpublished data).

Of the six polymorphic loci found in An. intermedius, only LAP1 and LAP2 were significant (Table I). Deviation from Hardy-Weinberg equilibrium was due in part to the large number of homozygotes found. In An. mattogrossensis, two loci (EST 1 and PGM) also presented significant deviations from their expected allelic frequencies. For EST1 was due to heterozygote deficiency. For PGM, deviation was related to heterozygote excess. Heterozygote deficiency was seen in an An. albitarsis population from Macapá (Amapá) for EST4 and LAP1 loci (Maia 1997). When studying An. nuneztovari populations from Brazil and from Colombia, Hardy-Weinberg disequilibrium was found for some loci, favoring homozygotes excess for a rare allele of EST5 and PGM loci, or heterozygotes individuals constituted by two rare alleles of IDH1 and MDH loci (Scarpassa et al. 1999). A large number of homozygotes was verified for some loci in An. darlingi populations from the Amazon Region, except for the EST2 locus in the Manaus population, in which the heterozygotes were more frequent (Santos et al. 1999).

Lower heterozygosity values were obtained for $A n$. intermedius and An. mattogrossensis when compared to species belonging to Nyssorhynchus and Anopheles subgenera (Table III). However, difference in the mean heterozygosity values for An. intermedius and An. mattogrossensis is not great enough to reject the possibility that the difference is due to random sampling variability. 


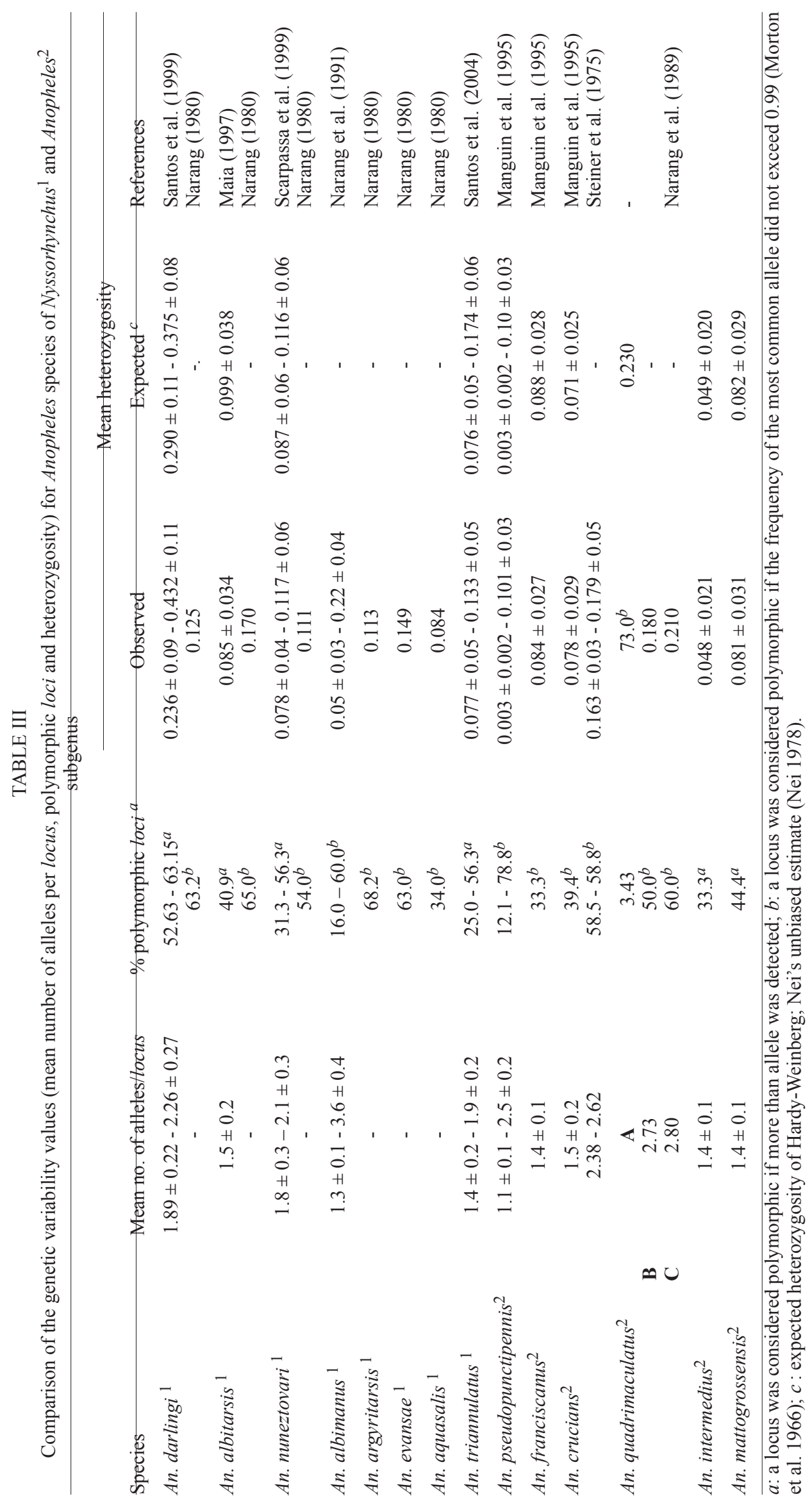


Species or populations distributed in a large variety of environmental conditions would probably be more genetically heterozygous and/or polymorphic. Contrarily, populations of limited or restricted distribution in special habitats would be less polymorphic (Narang 1980). Low heterozygosity (0.084) found in An. aquasalis suggested this to be an strategy of the species, because larvae breed in brackish water, mainly restricted to the coastal region (Narang 1980).

High heterozygosity values were found for $\mathrm{An}$. $\mathrm{Cru}$ cians (Steiner et al. 1975) and species A, B, and C of the An. quadrimaculatus complex (Narang et al. 1989), that are vectors species of the subgenus Anopheles. However, the An. pseudopunctipennis population from Granada Island differed from those in the continent on account of lacking heterozygotes and low polymorphism, due to their geographical isolation, suggesting this low level of genetic variability to be brought about by "founder effect" (Manguin et al. 1995).

Data on genetic distance values $(\mathrm{D}=0.683)$ of $A n$. intermedius and An. mattogrossensis are consistent with those found in the literature for interespecific variation in Anopheles subgenus (Manguin et al. 1995). These authors identified lower distance values $(\mathrm{D}=0.335)$ between the closely related species, An. pseudopunctipenis and An. franciscanus, when compared with An. crucians $(\mathrm{D}=0.997)$. Higher value $(\mathrm{D}=2.355)$ was observed between An. pseudopunctipenis and An. (Nys.) albimanus. However, Santos et al. (2003) found lower values (D = 0.373 - 0.989) among five Anopheles species belonging to the Nyssorhynchus and Anopheles subgenera from the Amazon Region. In An. rangeli and An. trinkae, the genetic distance ranged from $0.149 \leq \mathrm{D} \leq 0.197$ and between these two species and An. nuneztovari it ranged from $0.286 \leq \mathrm{D} \leq 0.440$ (Fritz et al. 1995), both of the Nyssorhynchus subgenus.

The genetic identity $(\mathrm{I}=0.382)$ found between $A n$. intermedius and An. mattogrossensis agrees with the values proposed by Avise (1974) for cogeneric populations $(0.26 \leq \mathrm{I} \leq 0.67)$.

Low heterozygosity and isoenzyme polymorphism found in An. intermedius and An. mattogrossensis populations agree with data found in literature for species of restricted distribution of the subgenus Anopheles and some of the subgenus Nyssorhynchus, and it differs from most malaria vector species. Nonetheless, An. intermedius and An. mattogrossensis can be considered highly specialized species since they can be found only in restricted spotted niches in spite of showing a wide geographical distribution. An. intermedius is found mainly in the border between the primary forest and cattle pastures, while $A n$. mattogrossensis is found in swamps or shallow flooded areas. The low variability found in these two species is probably related to the specialized ability to thrive on the niches they occupy rather than to their large geographical distribution. The low variability can also be a result of $A n$. intermedius and An. mattogrossensis' genetic structures, where selection pressures were not enough to lead to higher variability.

\section{ACKNOWLEDGMENTS}

To the technicians of the Malaria and Dengue Vectors Laboratory for their technical support in the collections and identification of the mosquitoes. To Jorge Antunes for helping draft the original English version of the text.

\section{REFERENCES}

Arruda M, Carvalho MB, Nussenzweig RS, Maracic M, Ferreira AW, Cochrane AH 1986. Potential vectors of malaria and their different susceptibility to Plasmodium falciparum and Plasmodium vivax in Northern Brazil identified by immunoassay. Am J Trop Med Hyg 35: 873-881.

Avise JC 1974. Systematic value of electrophoretic data. Syst Zool 23: 465-481.

Belkin JN, Schick RX, Heinemann SJ 1971. Mosquitoes studies (Diptera: Culicidae). XXV. Mosquitoes originally described from Brazil. Contrib Amer Ent Inst 7: 1-18.

Carvalho-Pinto CJ, Lourenço-de-Oliveira R 2004. Isoenzimatic analysis of four Anopheles (Kerteszia) cruzii (Diptera: $\mathrm{Cu}-$ licidae) populations of Brazil. Mem Inst Oswaldo Cruz 99: 471-475.

Consoli RAGB, Lourenço-de-Oliveira R 1994. Principais Mosquitos de Importância Sanitária no Brasil, Fiocruz, Rio de Janeiro, 228 pp.

Cova-Garcia P, Sutil E 1977. Claves Gráficas para la Clasificación de Anofelinos de Venezuela, Ministerio de Sanidad y Asistencia Social, Division de Endemias Rurales, Direccion de Malariologia y Saneamento Ambiental, Maracay, Aragua, Venezuela, $91 \mathrm{pp}$.

Forattini OP 1962. Entomologia Médica, Faculdade de Higiene e Saúde Pública, São Paulo, v. 1, 662 pp.

Fritz GN, Bermudez H, Seawright JA 1995. Genetic differentiation and diagnostic loci of Anopheles nuneztovari, Anopheles trinkae and Anopheles rangeli (Diptera: Culicidae). J Med Entomol 32: 663-672.

Lanzaro GC, Narang SK, Seawright JA 1990. Speciation in an anopheline (Diptera: Culicidae) mosquito: enzyme polymorphism and the genetic structure of populations. Ann Entomol Soc Am 83: 578-585.

Lima LMKS, Contel EPB 1990. Electrophoretic analysis of 12 proteins in natural populations of Spodoptera frugiperda (Lepidoptera: Noctuidae). Rev Brasil Genet 13: 711-729.

Maia JF 1997. Variabilidade Genética em Populações Naturais de Anopheles (Nyssorhynchus) albitarsis Lynch-Arribálzaga, 1878 (Diptera: Culicidae), MSc Thesis, Instituto Nacional de Pesquisas da Amazônia, Manaus, 118 pp.

Manguin S, Roberts DR, Peyton EL, Fernandez-Salas I, Barreto M, Fernandez-Loayza R, Spinola RE, Martinez-Granaou R, Rodriguez MH 1995. Biochemical systematics and population genetic structure of Anopheles pseudopunctipennis, vector of malaria in Central and South America. Am J Trop Med Hyg 53: 362-377.

Monjeló LAS 2005. Processos de estimação das freqüências gênicas. In Genética de Populações. http://www.icb. ufam. edu.br/LABS/livro/livro.html

Morton NE, Krieger H, Mi MP 1966. Natural selection of polymorphism in Northeast Brazil. Am J Hum Genet 28: 153-172. 
Narang S 1980. Genetic variability in natural populations, evidence in support of the selectionist view. Experientia 36: 50-51.

Narang SK, Seawright JA, Suarez MF 1991. Genetic structure of natural populations of Anopheles albimanus in Colombia. J Am Mosq Control Assoc 7: 437-445.

Narang SK, Toniolo SR, Seawright JA, Kaiser PE 1989. Genetic differentiation among sibling species A, B and C of the Anopheles quadrimaculatus Complex (Diptera: Culicidae). Ann Entomol Soc Am 82: 508-515.

Nei M 1978. Estimation of average heterozygosity and genetic distance from a small number of individuals. Genetics 89: 583-590.

Rodriguez GAD, Santos JMM, Maia JF 2000. Ontogenetic patterns and genetic variation in Anopheles (Anopheles) intermedius Chagas, 1908 and Anopheles (Anopheles) mattogrossensis Lutz \& neiva, 1911 (Diptera: Culicidae) in the Brazilian Amazon. Rev Brasil Biol 60: 341-351.

Santos JMM, Contel EPB, Kerr WE 1981. Biologia de anofelinos amazônicos. I. Ciclo biológico, postura e estádios larvais de Anopheles darlingi Root, 1926 (Diptera: Culicidae) da Rodovia Manaus/Boavista. Acta Amazonica 11: 789-797.

Santos JMM, Lobo JA, Tadei WP, Contel EPB 1999. Intrapopulational genetic differentiation in Anopheles (N.) darlingi Root, 1926 (Diptera: Culicidae) in the Amazon region. Genet Molec Biol 22: 325-331.

Santos JMM, Maia JF, Tadei WP 2004. Differentiation and genetic variability in natural populations of Anopheles (N.) triannulatus (Neiva \& Pinto, 1922) of Brazilian Amazonia. Rev Bras Biol 64: 327-336.
Santos JMM, Maia JF, Tadei WP, Rodriguez GAD 2003. Isoenzymatic variability among five Anopheles species of the Amazon Region, Brazil. Mem Inst Oswaldo Cruz 98: 247-253.

Santos JMM, Tadei WP, Contel EPB 1996. Electrophoretic analysis of 11 enzymes in natural populations of Anopheles (N.) darlingi Root, 1926 (Diptera: Culicidae) in the Amazon region. Acta Amazonica 26: 97-114.

Scarpassa VM, Tadei WP, Suarez MF 1999. Population structure and genetic divergence in Anopheles nuneztovari (Diptera: Culicidae) from Brazil and Colombia. Am J Trop Med Hyg 60: 1010-1018.

Steiner WWM, Joslyn DJ 1979. Electrophoretic techniques for the genetic study of mosquitoes. Mosq News 39: 35-54.

Steiner WWM, Joslyn DJ, Steiner JA 1975. Genetic Studies of Mosquitoes. I. Genetic Variation in Anopheles crucians, Provisional Department of Genetics and Development, University of Illinois, Urbana, $14 \mathrm{pp}$.

Swofford DL, Selander RB 1981. Biosys-1: a Fortran program for the comprehensive analyses of electrophoretic data in population genetics and systematics. J Hered 72: 281-283.

Tadei WP 1993. Biologia de anofelinos amazônicos. XVIII. Considerações sobre as espécies de Anopheles (Culicidae), transmissão e controle da malária na Amazônia. Rev UA Série: Ciências da Saúde 2: 1-34.

Tadei WP, Dutary-Thatcher B 2000. Malaria vectors in the Brazilian Amazon: Anopheles of the subgenus Nyssorhynchus. Rev Inst Med Trop São Paulo 42: 87-94. 